\title{
A REVIEW TO “ACCIDENTAL BROTHERS”
}

\author{
John Archer \\ Emeritus Professor of Psychology, University of Central Lancashire, UK \\ JArcher@uclan.ac.uk
}

A Review of the Book

\section{Accidental Brothers: The Story of Twins Exchanged at Birth and the Power of Nature and Nurture}

By Nancy L Segal and Yesika S. Montoya . 2018.

St. Martin's Press, New York, NY. 352 pages.

ISBN 978-125-010-190-7 (Hardcover Edition, \$26.99, USD)

Twin studies have been used to make inferences about the relative contributions of nature and nurture to human behaviour. Nancy Segal is well-known for her twin studies and for adopting an evolutionary framework when viewing these studies (e.g., Segal, 1988, 1993). The basic premise is that identical (monozygotic: MZ) twins reared in different environments, typically through being adopted or fostered into different homes, can be compared to dizygotic (DZ) twins similarly reared apart. MZ twins share the same genes (coefficient of relatedness 100\%) whereas DZ twins share half of those genes that are uncommon in the general population (coefficient of relatedness 50\%). Typically, these studies find greater psychological and behavioural similarities between MZ twins reared apart than DZ twins reared apart. Critics of the inference that this indicates a substantial genetic influence on the traits measured, point out that the similarities between MZ twins could have arisen from similarities in the homes into which such twins are placed. Also, with fostered or adopted children, there is the knowledge of their status as twins.

One way of overcoming this potential problem would be to study cases where twins were accidentally switched between families shortly after birth, and this switch remained 
undetected until adulthood. Do such cases exist? As Segal and Montoya point out, wrongly assigned babies to mothers in hospital is likely to occur more often than is generally realised, leading to great problems for the families involved if and when the mistake is discovered. Many such cases are likely to have remained undetected.

Cases where one $\mathrm{MZ}$ twin is wrongly assigned to another mother whose baby is substituted for this twin, and the mistake is later discovered, are (as expected) very rare. In the families whose mothers gave birth to the twins, the baby substituted for the twin will typically be notably different from the twin. This is typically attributed to the substitute being a non-identical (DZ) twin, who is genetically related to the same extent as any other brother or sister, who are often rather different from one another.

Segal and Montoya indicate that nine switched-at-birth twin cases are known to researchers (p. 83; also Appendix 1, p. 275). Only two were double switches. One, from Puerto Rico, involved a MZ and a DZ pair, and the switch was discovered in the second year of life. There remains only one case where there was a double switch of MZ twins, and in which both were adults when switch became known. The book describes this unique case, which occurred in 1988 in Columbia, and which was discovered 25 years later. Yesika S. Montoya, who trained as a social worker, contacted Nancy Segal to enquire whether she would be interested in studying the Columbian twins, and their subsequent collaborative research forms the basis of this book.

Although the book is a detailed account of the two twin pairs, Jorge and William, and Carlos and William, their case is placed in the wider context of twin research, and what it can say about the nature-nurture problem. There are also many biographical details, so that by the end of the book the reader feels that he or she knows the two sets of twins, all four of whom acted as an "accidental brother" to one of another pair of twins, whose real twin-brother was elsewhere. The reader also gets to know the wider families of the twins, their rearing environments, their social relations and the problems for them and their families once the switch was discovered when they were in their mid-twenties.

Thus, several stories are interwoven in this book. One is the case of the two sets of twins themselves, who they are, and where they were brought up. Their environments were very different, Jorge and Carlos were reared in the city of Bogata, and William and Wilber in the remote countryside, their homes lacking the comforts of the city life, their lives involving hard farm work, in an area partially controlled by FARC guerrillas. Interwoven with the personal stories of the twins, the authors provide interesting information on other twin studies, showing for example cases of reunited twins wearing similar clothing, and showing the same idiosyncratic forms of behaviour.

The present case also enabled the authors to study what they referred to as VIRTUAL TWINS (VTs), who are genetically unrelated but reared as if they were fraternal twins. They tend to be much less alike in intellectual abilities and personality than DZ twins. The Columbian VTs believed that they were fraternal twins, in contrast to other cases, where the individuals knew that they were adopted (or that one was).

The course of events in Bogata that led to William and Jorge being reunited involved cases of mistaken identity, and the impact on these young adults of realising what must have happened. A later chapter tells of authors' trip to home of William \& Wilber in La Paz, rural Columbia. They go to the hospital where the switch must have taken place. This raises the question of whether recent mothers can recognise a newborn infant as her own, and how relatedness might be established both before and after DNA testing. Of 
course during human history and prehistory, before hospital births, this would not be a potential problem, contrasting with paternity which is inferred rather than demonstrated. It continues to be uncertain in many cases: in modern times, with DNA testing, people can pay a commercial company to find out "Who's your daddy?".

It is clear from the present case that there are strong genetic influences on a range of psychological and behavioural traits. As the authors put it on p. 163 "since the mid-1980s, studies of adult twins raised apart and together have shown that genetic factors influence political perspectives, social attitudes, divorce tendencies, financial decision-making, and religious involvement, behaviors previously thought to reflect how our parents raised us". It is also interesting that genetically-based choices become stronger with increasing age. To those who dismiss twin studies, saying that you cannot separate the influence of nature and nurture, this is only correct in one sense, that how we turn out to be at any time in our development results from the interaction of our genetic disposition with the environment (see Archer, 1992, pp. 58-67 for a fuller discussion). In this sense we cannot separate nature and nurture. But when we consider whether our genetic predisposition or our environment influences more strongly the outcome of this process in relation to a particular aspect of our psychology, for example our religious beliefs, we can find an answer from twin studies. The present study is of great importance since it involves two pairs of separated MZ twins whose rearing environments were very different, and who were not discovered for 25 years. The book is excellent in bringing out the human story behind the case study and weaving in scientific knowledge and issues raised by previous studies where relevant.

\section{ABOUT THE AUTHOR}

JOHN ARCHER, PhD, FBPsS, is the author of many articles on aggression, sex differences, and grief, from an evolutionary perspective. His books include "The behavioural biology of aggression" (1988), "The nature of grief" (1999), and "Sex and gender" (with Barbara Lloyd, 2002). He is former Editor-in-Chief of the journal Aggressive Behavior, and Life Fellow of the International Society for Research on Aggression. 


\section{REFERENCES}

Archer, J. (1992). Ethology and human development. Savage, MD: Barnes \& Noble (UK: Hemel Hempstead,: Harvester-Wheatsheaf).

Segal, N.L. (1988). Cooperation, competition, and altruism in human twinships: a sociobiological approach. In K.B. MacDonald (ed.), Sociobiological perspectives on human development (pp. 168-206). New York: Springer-Verlag. DOI

Segal, N.L. (1993). Twin, sibling, and adoption methods: Tests of evolutionary hypotheses. American Psychologist, 48(9), 943-956. DOI 